Daniel J. Cole MD, Della M. Lin MD, John C. Drummond MD, Harvey M. Shapiro MD

\title{
Spinal tetracaine de- creases central nervous system metabolism during somatosensory stimulation in the rat
}

The influence of spinal tetracaine on central nervous system (CNS) metabolism was determined during nociceptive stimulation. Rats were divided into a halothane group in which the sciatic nerve was stimulated during 0.5 per cent halothane anaesthesia, a tetracaine group in which the sciatic nerve was stimulated during a simultaneous tetracaine spinal and 0.5 per cent halothane anaesthetic, or an awake group. Autoradiographic determination of local spinal cord and cerebral glucose utilization was performed using ${ }^{14} \mathrm{C}-2 \cdot$ deoxyglucose. Central nervous system metabolism was greater in the halothane group than the tetracaine and awake groups $(P<0.05)$. The only meaningful differences berween the tetracaine and awake groups were in two lumbar grey areas at the site of drug administration where metabolism was decreased in the tetracaine/stimulated group. These results indicate that spinal tetracaine effects a decrease in metabolism locally, and attenuates increases in metabolism throughout the CNS observed during somatosensory stimulation.

Nous avons mesuré par autoradiographie au ${ }^{14} \mathrm{C}$-2déoxyglucose, l'effet d' une injection spinale de tétracaïne sur le métabolisme du cerveau et de la moelle épinière lors d'une stimulation douloureuse. On stimulait le nerf sciatique des rats du groupe halothane, anesthésiés avec de l'halothane d 0,5 pour cent et on faisait de même avec ceux du groupe têtracaïne auquel

\author{
Key words \\ ANAESTHETICS, LOCAL: tetracaine; \\ ANAESTHETIC TECHNIQUES: spinal anaesthesia; \\ ANAESTHETICS, VOLATILE: halothane; \\ BRAIN: metabolism; \\ SPINAL CORD: metabolism.
}

From the Departments of Anesthesiology, the Veteran's Administration Medical Center, San Diego, CA; the University of California at San Diego, La Jolla, CA; and Loma Linda University, Loma Linda, CA.

Address correspondence to: Dr. H. M. Shapiro, Department of Ancsthesiology, T-001, the University of California at San Diego, La Jolla, CA 92093. l'anesthésie à l'halothane 0,5 pour cent était associêe à un bloc spinal à la tétracaine. On disposait aussi d'un groupe éveillé (contrôle). L'activité métabolique cérébrale s'est avérée plus grande dans le groupe halothane que dans les deux autres $(P<$ $0,05)$. En fait, seul un métabolisme diminué dans les deux zones grises lombaires (au site de l'injection), distinguait le groupe tétracaïne du groupe éveillé. Il semble donc que la tétracaïne puisse réduire localement le métabolisme de la moelle épinière et entraver l'augmentation du métabolisme cérébral associée à une stimulation somatosensorielle.

Although the effect of general anaesthesia on central nervous system (CNS) metabolism has been extensively studied, ${ }^{1-11}$ there have been few investigations on the influence of spinal anaesthesia. ${ }^{13-15}$ The available data indicate that local anaesthetics administered in the spinal subarachnoid space decrease metabolism in the spinal cord to a degree comparable to that achieved in the brain during general anaesthesia. ${ }^{12}$ Previous studies on the effect spinal anaesthesia may have upon CNS metabolism have been performed in unstimulated animals, and conclusions have been restricted to the direct effects of the drug. As a relationship between the metabolic state and CNS function has been established, ${ }^{14}$ it is plausible that a drug which results in profound sensory and motor blockade also attenuates metabolic increases throughout the CNS associated with nociceptive stimuli. ${ }^{15,16}$ In addition, it is possible that a drug administered in the spinal subarachnoid space may affect cerebral metabolism, either by perturbation of ascending inhibitory/ stimulatory pathways, or by drug migration to the cerebrum and a resultant direct impact on cerebral metabolism.

The intent of the present study was to evaluate the influence of spinal anaesthesia upon spinal cord and cerebral metabolism during nociceptive stimulation.

\section{Methods}

Approval was obtained from the Institutional Animal Research Committee. The rate of glucose metabolism in 
spinal cord (1-SCMRg) and brain (1-CMRg) was determined in male Sprague-Dawley rats of similar weights during a 0.5 per cent halothane anaesthetic with continuous unilateral sciatic nerve stimulation $(\mathrm{Hal} / \mathrm{S})$, during a 0.5 per cent halothane and spinal tetracaine anaesthetic with continuous unilateral sciatic nerve stimulation (Tet/ S); or during the awake state without stimulation (Awake/ $\mathrm{U})$. Each rat underwent the following preparation:

\section{Part 1}

During nitrous oxide $\left(\mathrm{N}_{2} \mathrm{O}\right)$ /halothane anaesthesia (via a face mask), a spinal catheter was placed in the subarachnoid space via the atlanto-occipital membrane, ${ }^{17}$ with the tip at $L_{1}$. The incision was infiltrated with 0.25 per cent bupivacaine. A five-day recovery period was allowed with daily neurological examinations of motor function, gait, and response to sensory stimuli. During the five-day recovery period each rat in the awake group was acclimatized to a plexiglass restraining cage for a period of four hours each day.

\section{Part 2}

One day prior to the metabolic study, the extent and duration of analgesia produced by $30 \mu l$ of one per cent tetracaine in five per cent dextrose (via the subarachnoid catheter) were determined in each rat. This was performed in order to assure that a complete lumbosacral block would be maintained during the metabolic study ( $45 \mathrm{~min}$ ). A complete lumbosacral block was defined as an absence of spontaneous lower extremity movement (proprioceptive response), and a negative response to fingerpinch of the lower paws and skin (noxious stimuli). A transient lower thoracic block was allowed; however, no upper thoracic or cervical block was permitted.

\section{Part 3}

On the day of the metabolic study each rat was anaesthetized in a $2.5 \mathrm{~L}$ plexiglass box with $\mathrm{N}_{2} \mathrm{O}$ ( 50 per cent) and halothane (two per cent). The tracheas of animals in the $\mathrm{Hal} / \mathrm{S}$ and Tet/S groups were intubated orally, and their lungs mechanically ventilated throughout the preparatory and study period. ${ }^{18}$ An air/oxygen mixture $\left(\mathrm{FiO}_{2}-0.4\right)$ and one per cent halothane were administered during the preparatory period $(30 \mathrm{~min})$. In the awake group of animals, the anaesthetic and respiratory gases were delivered via a face mask. An arterial catheter was inserted in the right femoral artery for continuous blood pressure monitoring. A venous catheter was inserted in the right femoral vein for drug, fluid and isotope administration. A low dead space $(6 \mu \mathrm{l})$, arterial-venous shunt with a sampling side arm was placed in the left groin for rapid blood collection. In the halothane and tetracaine groups of animals, a platinum electrode was implanted in the left sciatic nerve. Physiological variables $(\mathrm{pH}$, $\mathrm{PaCO}_{2}, \mathrm{PaO}_{2}$, mean arterial pressure (MAP), serum glucose, and haematocrit) were monitored and recorded immediately before and during the metabolic study. Rectal temperature (Yellow Springs Instruments ${ }^{\circledR}$ ) was servo-controlled at $37^{\circ} \mathrm{C}$. An $\mathrm{FIO}_{2}$ of 0.4 was delivered to each rat during the metabolic study. At the conclusion of the preparatory period the halothane concentration was decreased to 0.5 per cent for the animals in the halothane and tetracaine groups (this dose was sufficient to prevent movement in response to somatosensory stimulation). A 90 min stabilization period was allowed during which the rats were not disturbed. Each rat in the awake group was allowed a $90 \mathrm{~min}$ anaesthetic recovery period. Following anaesthetic recovery (awake group) or stabilization (halothane and tetracaine groups), $30 \mu \mathrm{l}$ of saline (awake and halothane groups) or $30 \mu$ lof one per cent tetracaine in five per cent dextrose was administered via the subarachnoid catheter. In animals in the halothane and tetracaine groups, following saline or tetracaine administration (three minutes) continuous stimulation of the sciatic nerve was begun and maintained throughout the metabolic study with a Grass $S 44-B^{\circledR}$ nerve stimulator (10 volts, $0.5 \mathrm{~ms}$, and $10 \mathrm{~Hz}$ ).

In summary, one of the following anaesthetic/stimulus states was present during I-CMRg/I-SCMRg determination.

1 Halothane/Stimulated $(\mathrm{Hal} / \mathrm{S})(n=10)$. Halothane anaesthesia ( 0.5 per cent) was administered during the metabolic study. Five minutes before the $1-C M R g /$ I-SCMRg study, $30 \mu$ l of preservative-free saline was given in the spinal subarachnoid space. Continuous somatosensory stimulation was maintained throughout the metabolic study as described above.

2 Tetracaine/Halothane/Stimulated $(\mathrm{Tet} / \mathrm{S})(n=10)$. Halothane anaesthesia ( 0.5 per cent) was administered during the metabolic study. Five minutes before the I-CMRg/I-SCMRg study, $30 \mu \mathrm{l}$ of one per cent tetracaine in five per cent dextrose was given in the spinal subarachnoid space in order to achieve and maintain a complete lumbosacral block throughout the study. Continuous somatosensory stimulation was maintained throughout the metabolic study as described above.

3 Awake/Unstimulated (Awake/U $(n=10)$. Each rat in this group was awake and restrained during I-CMRg/ I-SCMRg determination. Five minutes before the metabolic study $30 \mu \mathrm{l}$ of preservative-free saline was given in the spinal subarachnoid space. No somatosensory stimulation was provided.

Autoradiographic determination of local spinal cord and cerebral glucose utilization was performed utilizing ${ }^{14} \mathrm{C}$-2-deoxyglucose $\left(100 \mathrm{Ci} \cdot \mathrm{kg}^{-1}\right) .{ }^{19}$ Twenty-six arterial blood samples $(50-100 \mu \mathrm{l})$ were collected over $45 \mathrm{~min}$ 
TABLE 1 Measured physiological data (mean \pm SD)

\begin{tabular}{lccc}
\hline & Awake & Halothane & Tetracaine \\
\hline Weight $(\mathrm{g})$ & $331 \pm 16$ & $339 \pm 23$ & $351 \pm 26$ \\
$\mathrm{pH}$ & $7.44 \pm 0.02$ & $7.45 \pm 0.03$ & $7.45 \pm 0.04$ \\
$\mathrm{PaO}_{2}(\mathrm{mmHg})$ & $104.9 \pm 13.6$ & $127.3 \pm 24.1$ & $126.7 \pm 23.2$ \\
$\mathrm{PaCO}_{2}(\mathrm{mmHg})$ & $37.9 \pm 2.6$ & $36.2 \pm 1.7$ & $37.8 \pm 2.8$ \\
Haematocrit $(\%)$ & $42 \pm 2$ & $40 \pm 3$ & $40 \pm 2$ \\
& & & \\
Mean Arterial & & $88 \pm 12^{*} \dagger$ & $70 \pm 10^{*} \dagger$ \\
Pressure (mmHg) & $112 \pm 14^{*}$ & $176 \pm 21 \dagger$ & $154 \pm 16 \dagger$ \\
Glucose (mg $\left.\cdot \mathrm{dl}^{-1}\right)$ & $168 \pm 28$ & $36.9 \pm 0.1$ & $37.0 \pm 0.2$ \\
Temperature $\left({ }^{\circ} \mathrm{C}\right)$ & $37.0 \pm 0.1$ & & \\
\hline
\end{tabular}

"Significant difference between awake group and the halothane and tetracaine groups $(P<0.05)$.

†Significant difference between the halothane and tetracaine groups $(P<0.05)$.

for determination of plasma glucose concentrations, and arterial ${ }^{14} \mathrm{C}$-2-deoxyglucose activity. At the conclusion of the study period the brain and spinal cord were removed rapidly and frozen in 2-methyl-isobutane at $-35^{\circ} \mathrm{C}$. The brain and spinal cord were cut in $20 \mu \mathrm{m}$ sections at 100 $\mu \mathrm{m}$ intervals using a cryostat at $-20^{\circ} \mathrm{C}$. Each section was dried on a hot plate $\left(60^{\circ} \mathrm{C}\right.$ ) and exposed with a set of six methylmethacrylate ${ }^{14} \mathrm{C}$ calibrated standards to singleemulsion $x$-ray film (Kodak OM- ${ }^{\circledR}$ ) for 21 days. Optical densities were determined on the brain and spinal cord sections by an auto-scanning densitometer with an aperature of $200 \mu \mathrm{m}$. All data were collected on-line with a Prime ${ }^{\circledR}$ computer for calculation of glucose utilization in 29 cerebral structures and 18 spinal cord areas using the lumped constants and operational equation described by Sokoloff. ${ }^{19}$

Statistical analysis was performed on the physiological and metabolic data using an analysis of variance, and a Bonferroni correction factor when appropriate. In addition, the stimulated and unstimulated sides (within a group) were compared by use of a paired t test. ${ }^{20} \mathrm{~A} P$ value of $<0.05$ was considered significant.

\section{Results}

A total of 31 rats was entered into the study. One rat was excluded because of a neurological deficit following placement of the subarachnoid catheter. The physiological variables recorded immediately before and during the metabolic study are presented in Table $\mathrm{I}$. There were no between groups differences in weight, $\mathrm{pH}, \mathrm{PaCO}_{2}, \mathrm{PaO}_{2}$, haematocrit, or temperature (see Table l). There were differences in MAP and serum glucose. The MAP (mean $\pm \mathrm{SD}$ ) was greater in the Awake/U group (112 \pm 14 $\mathrm{mmHg})$ than in the $\mathrm{Hal} / \mathrm{S}(88 \pm 12 \mathrm{mmHg})$ and Tet/S (70 $\pm 10 \mathrm{mmHg}$ ) groups. The MAP was also greater in the $\mathrm{Hal} / \mathrm{S}$ group than in the Tet/S group. The serum glucose (mean $\pm \mathrm{SD}$ ) was greater in the $\mathrm{Hal} / \mathrm{S}$ group $(176 \pm 21$ $\left.\mathrm{mg} \cdot \mathrm{dl}^{-1}\right)$ than in the Tet/S group $\left(154 \pm 16 \mathrm{mg} \cdot \mathrm{dl}^{-1}\right)$.

\section{Cerebral metabolism}

The I-CMRg data are provided in Table II. There were no side-to-side differences within any group for any of the structures evaluated. Cerebral metabolism was significantly increased in many of the structures for the Hal/S group (by up to 112 per cent) relative to the Tet/S and Awake/U groups $(P<0.05)$. Occasional small but significant differences were present between the Tet/S and Awake/U groups. These differences did not demonstrate a consistent pattern of change (i.e., sometimes greater in the Tet/S group, and sometimes greater in the Awake/U group).

\section{Spinal cord metabolism}

The I-SCMRg data are listed in Table III. There were no side-to-side differences (ipsilateral to stimulation vs contralateral to stimulation) in either the Awake/U or Tet/S groups. However, side-to-side differences were evident in the $\mathrm{Hal} / \mathrm{S}$ group. These side-to-side differences were present in all lumbar grey areas (substantia gelatinosa, nucleus proprius, and ventral horn), in one thoracic grey area (substantia gelatinosa), and in one thoracic white area (dorsal columns). In general, the values were greater in the $\mathrm{Hal} / \mathrm{S}$ group (by up to 140 per cent) than in the Awake/U and Tet/S groups $(P<0.05)$. There were no differences between the $A$ wake/U and Tet/S groups except in two lumbar grey areas (nucleus proprius and the ventral horn) in which I-SCMRg was less in the Tet/S group. With the exception of lumbar grey matter contralateral to stimulation, all white and grey areas had a greater level of metabolism in the Hal/S group than in the Awake/U group. Metabolism was greater in the $\mathrm{Hal} / \mathrm{S}$ group compared with the Tet/S group at every cervical and thoracic area, and several lumbar areas. However, no differences were observed in lumbar grey areas on the side contralateral to stimulation.

\section{Discussion}

The results of this study indicate that, in the presence of nociceptive stimulation, spinal tetracaine results in rates of spinal cord glucose utilization similar to those observed in awake unstimulated animals. The data further suggest that spinal anaesthesia with tetracaine blocks generalized increases in I-CMRg/I-SCMRg that apparently occur with somatosensory stimulation during light halothane anaesthesia. While not invariably true, a correlation between neural function and CNS metabolism has been demonstrated. ${ }^{14-16}$ The results of this study tend to confirm this correlation, as the data suggest that a drug (spinal tetracaine) that produced a functional transection 
TABLE II Local cerebral metabolism during halothanc anaesthesia $(0.5$ per cent $)$, spinal tetracaine administered during a halothane anaesthetic $(0.5$ per cent), or during the awake state. The left side was stimulated in the halothane and tetracaine group. Values are expressed as mean $\pm \mathrm{SE}\left(\mu \mathrm{mol} \cdot 100 \mathrm{~g}^{-1} \cdot\right.$ minute $\left.{ }^{-1}\right)$

\begin{tabular}{|c|c|c|c|c|c|c|}
\hline & \multicolumn{2}{|l|}{ Awake } & \multicolumn{2}{|l|}{ Halothane } & \multicolumn{2}{|c|}{ Tetracaine } \\
\hline & Left & Right & Left & Right & Left & Right \\
\hline \multicolumn{7}{|l|}{ Auditory system } \\
\hline Cortex & $94 \pm 5$ & $90 \pm 6$ & $136 \pm 18 * \dagger$ & $137 \pm 18^{* \dagger}$ & $97 \pm 6 \dagger$ & $97 \pm 6^{\dagger}$ \\
\hline Medial geniculate & $86 \pm 4$ & $83 \pm 4$ & $100 \pm 17$ & $98 \pm 17$ & $72 \pm 4 *$ & $74 \pm 6^{*}$ \\
\hline Inferior colliculus & $100 \pm 5$ & $98 \pm 5$ & $106 \pm 19$ & $110 \pm 18$ & $83 \pm 7^{*}$ & $83 \pm 8^{*}$ \\
\hline \multicolumn{7}{|l|}{ Visual system } \\
\hline Cortex & $72 \pm 6$ & $76 \pm 5$ & $131 \pm 16^{*} \dagger$ & $133 \pm 16^{* \dagger} \dagger$ & $98 \pm 8 * \dagger$ & $95 \pm 7 * \dagger$ \\
\hline Lateral geniculate & $58 \pm 4$ & $62 \pm 6$ & $57 \pm 7$ & $58 \pm 7$ & $44 \pm 4^{*} \dagger$ & $43 \pm 4^{* \dagger}$ \\
\hline Superior colliculus & $77 \pm 5$ & $76 \pm 3$ & $108 \pm 18$ & $108 \pm 18$ & $77 \pm 6$ & $77 \pm 6$ \\
\hline \multicolumn{7}{|l|}{ Sensorimotor system } \\
\hline Precentral cortex & $90 \pm 5$ & $87 \pm 5$ & $119 \pm 9 * \dagger$ & $119 \pm 9 * \dagger$ & $92 \pm 5 !$ & $95 \pm 5^{\dagger}$ \\
\hline Mid cortex & $88 \pm 5$ & $88 \pm 5$ & $117 \pm 11^{* \dagger}$ & $117 \pm 10^{* \dagger} \dagger$ & $88 \pm 4 \dagger$ & $91 \pm 6^{\dagger}$ \\
\hline Lateral cortex & $90 \pm 5$ & $94 \pm 5$ & $123 \pm 11^{* \dagger} \dagger$ & $125 \pm 11^{* \dagger}$ & $93 \pm 6 \dagger$ & $91 \pm 6 \dagger$ \\
\hline Ventral thalmus & $80 \pm 6$ & $79 \pm 6$ & $118 \pm 13^{*} \dagger$ & $119 \pm 12^{*} \dagger$ & $89 \pm 7 \dagger$ & $92 \pm 7 \dagger$ \\
\hline Dorsomedial thalamus & $8 I \pm 4$ & $82 \pm 4$ & $115 \pm 12^{*}$ & $115 \pm 12^{*+}$ & $90 \pm 7$ & $91 \pm 7$ \\
\hline Periventricular grey & $51 \pm 4$ & $49 \pm 6$ & $89 \pm 13^{*}$ & $88 \pm 13^{*}$ & $70 \pm 8^{*}$ & $70 \pm 8^{*}$ \\
\hline Cerebcllar grcy & $62 \pm 3$ & $58 \pm 4$ & $91 \pm 12^{*}$ & $92 \pm 12^{*}$ & $70 \pm 7$ & $71 \pm 6$ \\
\hline \multicolumn{7}{|l|}{ Extrapyramidal } \\
\hline Caudate-Putamen & $94 \pm 5$ & $90 \pm 4$ & $145 \pm 18 * \dagger$ & $147 \pm 17^{* \dagger}$ & $98 \pm 7 \dagger$ & $97 \pm 6 \dagger$ \\
\hline Globus pallidus & $76 \pm 6$ & $72 \pm 5$ & $71 \pm 12$ & $73 \pm 11$ & $57 \pm 6^{*}$ & $54 \pm 4^{*}$ \\
\hline Substantia nigra & $60 \pm 5$ & $59 \pm 5$ & $86 \pm 14^{*}$ & $88 \pm 14^{*}$ & $68 \pm 5$ & $68 \pm 6$ \\
\hline \multicolumn{7}{|l|}{ Limbic system } \\
\hline Claustrum & $69 \pm 4$ & $72 \pm 5$ & $119 \pm 18 * \dagger$ & $122 \pm 15^{* \dagger}$ & $76 \pm 7 \dagger$ & $76 \pm 6 !$ \\
\hline Septal nucleus & $57 \pm 4$ & $57 \pm 4$ & $83 \pm 14^{*}$ & $83 \pm 14^{*}$ & $61 \pm 4$ & $61 \pm 4$ \\
\hline Piriform cortex & $81 \pm 4$ & $78 \pm 5$ & $114 \pm 14^{*} \dagger$ & $115 \pm 13 * \dagger$ & $78 \pm 4 t$ & $80 \pm 5+$ \\
\hline Amygdala & $67 \pm 3$ & $65 \pm 4$ & $91 \pm 12^{*}+$ & $91 \pm 13^{* \dagger}$ & $72 \pm 4$ & $71 \pm 4$ \\
\hline Hypothalamus & $64 \pm 5$ & $67 \pm 4$ & $89 \pm 14$ & $89 \pm 14$ & $62 \pm 3$ & $61 \pm 3$ \\
\hline \multicolumn{7}{|l|}{ Hippocampus } \\
\hline Dentate gyrus & $50 \pm 3$ & $53 \pm 4$ & $106 \pm 13^{* \dagger}$ & $109 \pm 12 * \dagger$ & $78 \pm 7 *+$ & $78 \pm 7^{*} \dagger$ \\
\hline Ammons horn & $67 \pm 3$ & $67 \pm 4$ & $104 \pm 13^{*} \dagger$ & $105 \pm 12 * \dagger$ & $76 \pm 6 \dagger$ & $76 \pm 6 \dagger$ \\
\hline \multicolumn{7}{|l|}{ Ventral hippocampus } \\
\hline$(\mathrm{CA} I+\mathrm{CA} 3)$ & $60 \pm 5$ & $59 \pm 6$ & $100 \pm 14 * \dagger$ & $103 \pm 14^{*} \dagger$ & $73 \pm 7 *+$ & $72 \pm 6^{* \dagger}$ \\
\hline \multicolumn{7}{|l|}{ Myelinated fibre tracts } \\
\hline Corpus callosum & $46 \pm 4$ & $49 \pm 4$ & $79 \pm 14^{*} \dagger$ & $79 \pm 14 * \dagger$ & $48 \pm 4 \dagger$ & $49 \pm 4 \dagger$ \\
\hline Intemal capsule & $50 \pm 4$ & $50 \pm 4$ & $70 \pm 11$ & $69 \pm 10 \dagger$ & $49 \pm 4$ & $47 \pm 3 t$ \\
\hline Cerebellar white & $40 \pm 4$ & $43 \pm 4$ & $77 \pm 11^{*}$ & $76 \pm 11^{*}$ & $64 \pm 6^{*}$ & $68 \pm 6^{*}$ \\
\hline \multicolumn{7}{|c|}{ Cerebral association areas } \\
\hline Frontal cortex & $91 \pm 5$ & $94 \pm 5$ & $136 \pm 20^{*} \dagger$ & $134 \pm 19 * \dagger$ & $83 \pm 7 \dagger$ & $81 \pm 7 \dagger$ \\
\hline Reticular formation & $69 \pm 4$ & $69 \pm 4$ & $94 \pm 16^{*}$ & $93 \pm 16^{*}$ & $76 \pm 3$ & $75 \pm 3$ \\
\hline
\end{tabular}

*Difference from the awake group at $P<0.05$.

$\dagger$ Difference between the halothane and tetracaine groups at $P<0.05$.

of the spinal cord also resulted in substantial metabolic decreases throughout the neuroaxis by deafferentiation of noxious stimuli.

One methodological concern was the choice of halothane ( 0.5 per cent) as a basal anaesthetic in the two stimulated groups. During somatosensory stimulation, a basal halothane anaesthetic ( 0.5 per cent) was administered in order to prevent movement to stimulus. It is possible that this dose of halothane $\left(1 / 2 \mathrm{MAC}^{21}\right)$ had an effect upon the metabolic state of the spinal cord. However, as spinal cord metabolism is only slightly reduced (12-35 per cent) in rats during 1.2 per cent 
TABLE II] Local spinal cord metabolism during halothane anaesthesia ( 0.5 per cent), spinal tetracaine administered during a halothane anaesthetic $(0.5$ per cent), or during the awake state. The left side was stimulated in the halothane and the tetracainc group. Values are expressed as mean $\pm \mathrm{SE}\left(\mu \mathrm{mol} \cdot 100 \mathrm{~g}^{-1} \cdot \operatorname{minute}^{-1}\right)$

\begin{tabular}{|c|c|c|c|c|c|c|}
\hline & \multicolumn{2}{|l|}{ Awake } & \multicolumn{2}{|l|}{ Halothane } & \multicolumn{2}{|c|}{ Tetracaine } \\
\hline & Left & Right & Left & Right & Left & Right \\
\hline \multicolumn{7}{|l|}{ Cervical grey } \\
\hline Sub. gelatinosa & $29 \pm 3$ & $29 \pm 3$ & $47 \pm 3 *+$ & $44 \pm 3 * \dagger$ & $32 \pm 3 \dagger$ & $31 \pm 3 \dagger$ \\
\hline Nucleus propius & $31 \pm 3$ & $31 \pm 2$ & $42 \pm 3^{*} \dagger$ & $33 \pm 3^{*} \dagger$ & $33 \pm 4 \dagger$ & $34 \pm 4 \dagger$ \\
\hline Ventral horn & $39 \pm 2$ & $38 \pm 3$ & $49 \pm 5^{* \dagger}$ & $48 \pm 4^{* \dagger}$ & $40 \pm 5 \dagger$ & $40 \pm 4 \dagger$ \\
\hline \multicolumn{7}{|l|}{ Cervical white } \\
\hline Dorsal & $16 \pm 2$ & $16 \pm 2$ & $26 \pm 3^{*} \dagger$ & $25 \pm 3^{*} \dagger$ & $16 \pm 3 t$ & $15 \pm 3 \dagger$ \\
\hline Lateral & $20 \pm 3$ & $20 \pm 2$ & $29 \pm 3^{* \dagger}$ & $31 \pm 3 * \dagger$ & $19 \pm 3+$ & $18 \pm 3 \dagger$ \\
\hline Ventral & $19 \pm 3$ & $20 \pm 3$ & $28 \pm 3^{*} \dagger$ & $30 \pm 3^{*} \dagger$ & $18 \pm 3 \dagger$ & $18 \pm 3 \dagger$ \\
\hline \multicolumn{7}{|l|}{ Thoracic grey } \\
\hline Sub. gelatinosa & $25 \pm 3$ & $27 \pm 3$ & $55 \pm 4 * \dagger \ddagger$ & $48 \pm 4^{*} \dagger \ddagger$ & $33 \pm 4 \dagger$ & $33 \pm 5 \dagger$ \\
\hline Nucleus propius & $31 \pm 2$ & $34 \pm 2$ & $47 \pm 5^{* \dagger}$ & $45 \pm 4^{*} \dagger$ & $29 \pm 3 \dagger$ & $29 \pm 3 \dagger$ \\
\hline Ventral horn & $33 \pm 3$ & $31 \pm 2$ & $48 \pm 5^{* \dagger}$ & $44 \pm 4^{* \dagger}$ & $29 \pm 3 \dagger$ & $30 \pm 4 \dagger$ \\
\hline \multicolumn{7}{|l|}{ Thoracic white } \\
\hline Dorsal & $14 \pm 2$ & $13 \pm 2$ & $39 \pm 4 * \dagger \ddagger$ & $32 \pm 4 * \dagger \ddagger$ & $16 \pm 3 \dagger$ & $16 \pm 3 \dagger$ \\
\hline Lateral & $15 \pm 2$ & $15 \pm 2$ & $35 \pm 4 * \dagger$ & $34 \pm 4 *+$ & $16 \pm 3 \dagger$ & $16 \pm 3 \dagger$ \\
\hline Ventral & $15 \pm 2$ & $15 \pm 3$ & $34 \pm 4^{* \dagger}$ & $34 \pm 4^{* \dagger}$ & $16 \pm 3+$ & $16 \pm 3 \dagger$ \\
\hline \multicolumn{7}{|l|}{ Lumbar grey } \\
\hline Sub. gclatinosa & $30 \pm 3$ & $31 \pm 3$ & $60 \pm 7^{*}+\ddagger$ & $37 \pm 5 \ddagger$ & $32 \pm 4 \dagger$ & $31 \pm 5$ \\
\hline Nucleus propius & $40 \pm 2$ & $43 \pm 2$ & $54 \pm 7^{*} \dagger \ddagger$ & $40 \pm 6 \ddagger$ & $31 \pm 5^{* \dagger}$ & $30 \pm 5^{*}$ \\
\hline Ventral horn & $40 \pm 2$ & $41 \pm 3$ & $48 \pm 6^{*}+ \pm$ & $42 \pm 6 \ddagger$ & $32 \pm 4 * \dagger$ & $32 \pm 5^{*}$ \\
\hline \multicolumn{7}{|l|}{ Lumbar white } \\
\hline Dorsal & $13 \pm 2$ & $13 \pm 2$ & $27 \pm 6^{* \dagger}$ & $24 \pm 5^{*+}$ & $12 \pm 3 \dagger$ & $12 \pm 3 \dagger$ \\
\hline Lateral & $17 \pm 2$ & $18 \pm 2$ & $30 \pm 6^{*} \dagger$ & $28 \pm 5^{*+}$ & $18 \pm 4 \dagger$ & $18 \pm 5 t$ \\
\hline Ventral & $19 \pm 2$ & $19 \pm 2$ & $26 \pm 5^{*}+$ & $24 \pm 4 * \dagger$ & $16 \pm 4 \dagger$ & $16 \pm 4 t$ \\
\hline
\end{tabular}

*Difference from the wake group at $P<0.05$.

†Difference between the halothane and tetracaine groups at $P<0.05$.

$\ddagger$ Difference between the left and right side within groups at $P<0.05$.

halothane (compared with awake controls), ${ }^{22}$ it is likely that the qualitative results of this study are real and were minimally affected by the halothane anaesthetic.

The nociceptive afferent pathway entails a stimulus at a peripheral nociceptor (sciatic nerve) which enters the spinal cord through the tract of Lissauer and substantia gelantinosa. The stimulus may cross to lateral and ventral spinothalamic tracts; or proceed ipsilaterally through the dorsal columns with subsequent decussation. The spinothalamic tracts either project directly to the thalamus where the stimulus is projected to the somatosensory area of the cortex, or relay at the reticular formation prior to thalamic synapse. These tracts decussate making it difficult to correlate rigidly the metabolic effect of a drug at specific anatomical sites to a specific pathway during somatosensory stimulation. ${ }^{23-25}$ It is for this reason that lumbar side-to-side differences present in the halothane group subsided in spinal cord area more distal to stimulus application.

In an evaluation of the effect of somatosensory stimulation upon central nervous system metabolism during pentobarbital or nitrous oxide anaesthesia, Crosby et al. ${ }^{15}$ demonstrated marked increases in I-SCMRg in the dorsal horn of the spinal cord, and minor increases in the brain during stimulation. Ginsberg et al. ${ }^{16}$ demonstrated significant increases in cerebral metabolism when the whiskers of a rat were stimulated during the awake state. Accordingly, it is not unexpected to observe metabolic increases throughout the central nervous system during somatosensory stimulation. However, the magnitude of the response in the present study was surprising. It is noteworthy that an anaesthetic ( 0.5 per cent halothane) that was sufficient to prevent movement of the animal in response to somatosensory stimulation none-the-less allowed suffi- 
cient afferent stimulus to result in increases in glucose utilization of up to 140 per cent in the halothane group, compared with the awake group and tetracaine groups.

When a tetracaine spinal anaesthetic was added to the baseline halothane anaesthetic, with few exceptions, the I-CMRg and I-SCMRg values were comparable to those observed during the awake state without somatosensory stimulation. This observation is consistent with a conclusion that spinal tetracaine blocks the normal cephalad propagation of nociceptive stimuli. This is supported by the absence of side-to-side asymmetry in I-SCMRg for the tetracine group compared to the asymmetry that was observed in the halothane group, and by the observation that the only I-SCMRg differences between the awake group and the tetracaine group were in spinal cord grey matter at the site of drug administration.

The decrease in I-SCMRg at the site of drug administration in the tetracaine group when compared with the awake and halothane groups is consistent with previous observations in which decreases in I-SCMRg of up to 21 per cent were observed with spinal bupivicaine. ${ }^{12}$

The modest differences in cerebral metabolism between the awake and the tetracaine groups may be attributable to the state of consciousness which may have effected the metabolic state of the brain. This restrictive hypothesis would be valid if: (1) spinal tetracaine blocks cephalad propagation of somatosensory stimulation, thus eliminating the stimulus as a difference between the awake and tetracaine groups; (2) if there was a neglible concentration of tetracaine in the brain; ${ }^{26-29}$ and (3) halothane $(0.5$ per cent) results in a neglible metabolic change in the central nervous system. ${ }^{11,22}$ All of these assumptions appear to be plausible.

In summary, spinal cord and cerebral metabolism were decreased when a tetracaine spinal anaesthetic was administered to animals receiving somatosensory stimulation when compared with a group of animals who did not receive spinal tetracaine. With the exception of a decrease in I-SCMRg in spinal grey matter local to tetracaine administration, I-SCMRg and I-CMRg was similar between the spinal tetracaine animals who were stimulated and an awake group of animals who were not stimulated. The results indicate that a tetracaine spinal anaesthetic blocks nociceptive neural traffic (and its accompanying metabolic increase), and may result in a direct decrease in spinal cord metabolism local to drug administration during somatosensory stimulation.

\section{Acknowledgements}

The authors gratefully acknowledge the technical assistance of Laura Breen, Michael Rathbun, and Elaine Shipko; and Jackie Breyer in the preparation of this manuscript.

\section{References}

1 Crosby $G$, Crane AM, Sokoloff $L$. A comparison of local rates of glucose utilization in spinal cord and brain in conscious and nitrous oxide or pentobarbitaltreated rats. Anesthesiology 1984; 61: 434-8.

2 Sakabe T, Tsutsui T, Maekawa T, Ishikawa T, Takeshita $H$. Local cerebral glucose utilization during nitrous oxide and pentobarbital anesthesia in the rat. Anesthesiology 1985; 63: 262-6.

3 Smith $A L$, Wollman $H$. Cerebral blood flow and matabolism: effects of anesthetic drugs and techniques. Anesthesiology 1972; 36: 378-400.

4 Shapiro HM. Anesthesia effects upon cerebral blood flow, cerebral metabolism, electrocncephalogram, and evoked potentials. In: Miller RD (Ed.). Anesthesia, 2nd cd. New York: Churchill-Livingstone, 1986: 1264-74.

5 Siesjö $B K$. Anaesthesia, analgesia, and sedation. In: Brain Energy and Metabolism. Chichester, New York: John Wiley \& Sons, 1978: 233-65.

6 Todd MM, Drummond JC, Shapiro HM. A comparison of the cerebrovascular and metabolic effect of the halothane and isoflurane in the cat. Anesthesiology 1984; 60: 276-82.

7 Cole DJ, Shapiro HM. Different 1.2 MAC combinations of nitrous oxide-enflurane cause unique local brain and spinal cord metabolic responses. Anesthesiology 1989; 70: 787-92.

8 Michenfelder JD. The interdependency of cerebral function and metabolic effects following massive doses of thiopental in the dog. Anesthesiology 1974; 41: 231-6.

9 Young ML, Smith DS, Greenberg J, Reivich M, Harp $J R$. Effects of sufentanil on regional cerebral glucose utilization in rats. Anesthesiology 1984; 61: 564-8.

10 Crosby $G$, Crane $A M$, Sokoloff $L$. Local changes in cerebral glucose utilization during ketamine anaesthesia. Anaesthesia 1982; 56: 437-43.

11 Savaki HE, Desban M, Glowinski J, Besson M. Local cerebral glucose consumption in the rat. I. Effects of halothane anesthesia. J Comp Neurol 1983; 213: 36-45.

12 Crosby $G$. Local spinal cord blood flow and glucose utilization during spinal anacsthesia with bupivacaine in conscious rats. Anesthesiology 1985; 63: 55-60.

13 Lin DM, Shapiro HM, Shipko EM. Comparison of epidural lidocaine and fentanyl on spinal cord metabolism during sensory stimulation. Anesthesiology 1985; 63: A232.

14 Sokoloff $L$. Relation between physiological function and energy metabolism in the central nervous system. J Neurochem 1977; 29: 13-26.

15 Crosby G, Crane AM, Jehle J, Sokoloff L. The local metabolic effect of somatosensory stimulation in the central nervous system of rats given pentobarbital or nitrous oxide. Anesthesiology 1983; 58: 38-43. 
16 Ginsberg $M D$, Dietrich WD, Busto R. Coupled forebrain increases of local cerebral glucose utilization and blood flow during physiologic stimulation of a somatosensory pathway in the rat: demonstration by double-label autoradiography. Neurology 1987; 37: 11-9.

17 Yaksh TL, Rudy TA. Chronic catheterization of the spinal subarachnoid space. Physiolog Behav 1976; 17: 1031-6.

18 Tran $D Q$. Lawson $D$. Endotracheal intubation and manual ventilation of the rat. Lab Animal Sci 1986; 36: 540-1.

19 Sokoloff $L$, Reivich $M$, Kennedy $C$ et al. The $\left[{ }^{14} \mathrm{C}\right]$ deoxyglucose method for the measurement of local cerebral glucose utilization: theory, procedure, and normal values in the conscious and anesthetized albino rat. $J$ Neurocem 1977; 28: 897-916.

20 Dixon WJ (Ed.). BMDP Statistical Software 1981. Program P7D. Los Angeles: University of Califomia Press, 1981: 104.

21 Cole DJ, Shapiro HM, Drummond JC, Kalichman $M W$. The non-linear anesthetic potency of nitrous oxide at sub-MAC levels in the rat. Anesth Analg 1989; 68: S57.

22 Crosby G, Atlas $S$. Local spinal cord metabolism in conscious and halothane-anaesthetized rats. Can J Anaesth 1988; 35: 359-63.

23 Lund $R D$, Webster $K E$. Thalamic afferents from the spinal cord and trigeminal nuclei: an experimental study in the rat. J Comp Neurol 1967; 30: 313-27.

24 Basbaum $A J$. Conduction of the effects of noxious stimulation by short-fiber multisynaptic systems of the spinal cord in the rat. Exp Neurol 1973; 40: 699-716.

25 Krishnan KRR, France RD, Erikkson L, Ellinwood EH. Neuroanatomy and neurophysiology of chronic pain. In: France RD, Krishnan KRR (Eds.). Chronic Pain. Washington: American Psychiatric Press, 1988: 30-41.

26 Greene NM. The central nervous system. In: Greene NM (Ed.). Physiology of Spinal Anesthesia. Baltimore: Williams and Wilkins, 1981: 45-54.

27 Post C, Freedman J. A ncw method for studying the distribution of drugs in spinal cord after intrathecal injection. Acta Pharmacol Toxicol 1984; 54: 253-7.

28 Stoelting $R K$. Local anesthetics. In: Stoelting RK (Ed.). Pharmacology and Physiology in Anesthetic Practice. Philadelphia: JB Lippincott, 1987: 148-68.

29 Tucker GT, Mather LE. Properties, absorption, and disposition of local anesthetic agents. In: Cousins MJ, Bridenbaugh PO (Eds.). Neural Blockade in Clinical Anesthesia and Management of Pain. Philadelphia: JB Lippincott, 1988: 47-110. 